\title{
Does limited right ventriculotomy prevent right ventricular dilatation and dysfunction in patients who undergo transannular repair of tetralogy of Fallot? Matched comparison of magnetic resonance imaging parameters with conventional right ventriculotomy long-term after repair
}

\author{
Cheul Lee, MD, PhD, ${ }^{a}$ Chang-Ha Lee, MD, ${ }^{a}$ Jae Gun Kwak, MD, ${ }^{a}$ Seong-Ho Kim, MD, ${ }^{b}$ \\ Woo-Sup Shim, MD, ${ }^{\mathrm{b}}$ Sang Yun Lee, MD, ${ }^{\mathrm{b}}$ Jae Suk Baek, MD, ${ }^{\mathrm{b}}$ So-Ick Jang, MD, ${ }^{\mathrm{b}}$ and \\ Yang Min Kim, MD
}

Objective: The objective of this study was to test the hypothesis that limited $(<1 \mathrm{~cm})$ right ventriculotomy (RV-tomy) in the setting of transannular tetralogy of Fallot (TOF) repair might result in less right ventricular (RV) dilatation and dysfunction compared with conventional RV-tomy.

\begin{abstract}
Methods: Between June 2002 and April 2012, 113 patients with transannular repair of TOF underwent magnetic resonance imaging (MRI). Patients were divided into a limited $\mathrm{RV}$-tomy group $(\mathrm{n}=39)$ and a conventional $\mathrm{RV}$-tomy group $(\mathrm{n}=74)$. Thirty-nine patients from each group were matched for comparison using propensity scores. The MRI parameters of the 2 groups were compared.
\end{abstract}

\begin{abstract}
Results: The interval between TOF repair and MRI examination was shorter in the limited RV-tomy group (limited, $12.7 \pm 3.8$ years; conventional, $17.2 \pm 4.7$ years; $P<.001$ ). Indexed $\mathrm{RV}$ volumes were similar between the groups (RV end-diastolic volume index: $149 \pm 31 \mathrm{~mL} / \mathrm{m}^{2}$ vs $152 \pm 42 \mathrm{~mL} / \mathrm{m}^{2} ; P=.704$. RV end-systolic volume index: $70 \pm 24 \mathrm{~mL} / \mathrm{m}^{2}$ vs $\left.77 \pm 38 \mathrm{~mL} / \mathrm{m}^{2} ; P=.313\right)$. There was no difference in the RV ejection fraction between the groups $(54 \% \pm 9 \%$ vs $51 \% \pm 9 \% ; P=.160)$. Propensity score-matched comparison also revealed no differences in $\mathrm{RV}$ volume and function.
\end{abstract}

Conclusions: No long-term benefits of limited RV-tomy were demonstrated compared with conventional RV-tomy in patients who underwent transannular TOF repair, at least in terms of RV volume and function. Further studies are necessary to define the role of limited RV-tomy in patients who undergo transannular TOF repair. (J Thorac Cardiovasc Surg 2014;147:889-96)

Surgical treatment of tetralogy of Fallot (TOF) has dramatically improved the outcome of this most common cyanotic heart defect. ${ }^{1,2}$ Currently, repair of TOF is being performed with low operative mortality. ${ }^{3,4}$ However, a substantial number of patients are exposed to chronic pulmonary regurgitation (PR) after repair if their pulmonary valve function cannot be preserved at the time of repair. The resultant chronic volume overload can lead to right ventricular (RV) dilatation, biventricular dysfunction,

\footnotetext{
From the Departments of Thoracic and Cardiovascular Surgery, ${ }^{\text {a }}$ Pediatric Cardiology, ${ }^{\mathrm{b}}$ and Radiology, ${ }^{\mathrm{c}}$ Cardiovascular Center, Sejong General Hospital, Bucheon, Republic of Korea.

Disclosures: Authors have nothing to disclose with regard to commercial support. Read at the 93rd Annual Meeting of The American Association for Thoracic Surgery, Minneapolis, Minnesota, May 4-8, 2013.

Received for publication April 29, 2013; revisions received Oct 23, 2013; accepted for publication Nov 11, 2013; available ahead of print Dec 23, 2013.

Address for reprints: Cheul Lee, MD, PhD, Department of Thoracic and Cardiovascular Surgery, Cardiovascular Center, Sejong General Hospital, 91-121 Sosa Bon 2-dong, Sosa-gu, Bucheon, Gyeonggi-do 422-711, Republic of Korea (E-mail: tscheul@hanmail.net).

$0022-5223 / \$ 36.00$

Copyright (c) 2014 by The American Association for Thoracic Surgery

http://dx.doi.org/10.1016/j.jtcvs.2013.11.019
}

heart failure symptoms, arrhythmias, and sudden death. ${ }^{5-7}$ Nowadays, pulmonary valve replacement (PVR) has become common practice to avoid the dreadful sequelae of chronic PR, although this procedure is not without problems. ${ }^{8-13}$

Traditionally, a transventricular approach with a large RV-tomy was commonly used for TOF repair. However, because late RV dilatation/dysfunction and an increased risk of ventricular arrhythmia were believed to be related, at least in part, to the presence of a large RV incision, a transatrial transpulmonary approach has been adopted by many centers to minimize or avoid these problems. ${ }^{14-16}$ With the transatrial approach, the RV incision, if any, can be limited to a short length just enough to relieve the RV outflow tract obstruction, usually less than $1 \mathrm{~cm}$. Even when a transannular incision is unavoidable, this so-called limited RV-tomy is believed to be superior to conventional large RV-tomy in terms of preventing RV dilatation and dysfunction in the long term. ${ }^{14,17}$ However, the long-term benefits of limited RV-tomy relative to conventional RVtomy in the setting of transannular TOF repair have not been demonstrated. The objective of this study was to test 


$$
\begin{aligned}
& \text { Abbreviations and Acronyms } \\
& \begin{array}{ll}
\text { EF } & =\text { ejection fraction } \\
\text { MRI } & =\text { magnetic resonance imaging } \\
\text { PR } & =\text { pulmonary regurgitation } \\
\text { PVR } & =\text { pulmonary valve replacement } \\
\text { RA } & =\text { right atrium } \\
\text { RV } & =\text { right ventricular } \\
\text { RV-tomy } & =\text { right ventriculotomy } \\
\text { TOF } & =\text { tetralogy of Fallot } \\
\text { VSD } & =\text { ventricular septal defect }
\end{array}
\end{aligned}
$$

the hypothesis that limited RV-tomy might result in less RV dilatation and dysfunction compared with conventional RVtomy in patients who underwent transannular TOF repair by analyzing magnetic resonance imaging (MRI) parameters.

\section{PATIENTS AND METHODS}

The institutional review board of our institution has approved this retrospective study and waived the need for individual patient consent.

\section{Study Population}

By searching the database of our institution, we identified 113 patients who had undergone MRI for evaluation of PR between June 2002 and April 2012 after transannular repair of TOF. A total of 1135 patients underwent TOF repair during the same period when the study population underwent TOF repair. Patients with other significant confounding congenital heart defects, significant (at least a moderate amount) regurgitation of other valves, poor MRI quality with resultant inaccurate volumetry data, and no information about the extent of the RV-tomy were excluded from this study. If a patient underwent multiple MRI examinations during follow-up, the latest examination was used for analysis. The medical records of these patients were reviewed.

\section{Operative Data at TOF Repair}

Thirty-nine patients $(34.5 \%)$ underwent limited $(<1 \mathrm{~cm}) \mathrm{RV}$-tomy and 74 patients $(65.5 \%)$ underwent conventional RV-tomy. There was an obvious trend favoring limited RV-tomy over conventional RV-tomy throughout the period when these patients underwent repair (Figure 1). This trend reflects the change in our center's approach for TOF repair as transatrial transpulmonary repair of TOF gained popularity. The ventricular septal defect (VSD) was closed through the RV in all patients who underwent conventional RV-tomy. For the limited RV-tomy group, the VSD was closed through the right atrium (RA) in 34 patients, through the RV in 4 patients with subarterial VSD, and through the RA/RV in 1 patient. Materials used for the transannular patch were autologous pericardium $(\mathrm{n}=65)$, bovine pericardium $(\mathrm{n}=17)$, Dacron $(\mathrm{n}=16)$, polytetrafluoroethylene (GoreTex; W.L. Gore \& Associates, Flagstaff, Ariz; $\mathrm{n}=3$ ), and no information $(n=12)$. Immediate postoperative pressure data by direct measurement were available for 72 patients $(63.7 \%)$, and the mean systolic pressure ratio between the right and left ventricles was $0.57 \pm 0.16$. There was no difference in the pressure ratio between limited and conventional RV-tomy groups $(0.55 \pm 0.15$ vs $0.59 \pm 0.16 ; P=.241)$.

\section{Cardiac MRI}

MRI studies were performed with a 1.5-Tesla Gyroscan Intera CV system (Philips Medical Systems, Best, The Netherlands). Biventricular volumetric analysis was performed using Extended MR Workspace software (Philips Medical Systems). The details of the MRI protocol

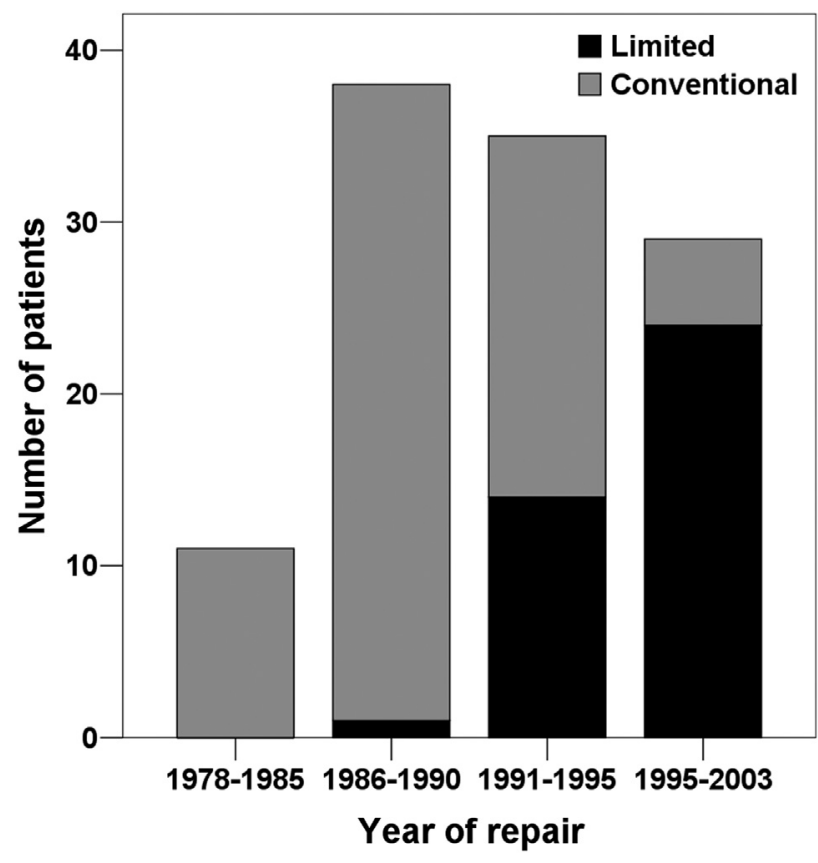

FIGURE 1. Distribution of limited versus conventional right ventriculotomy according to the year of repair.

used in our institution for assessment of patients with repaired TOF have been described previously. ${ }^{11}$

\section{Statistical Analysis}

SPSS version 18.0 (SPSS Inc, Chicago, Ill) was used for statistical analysis. Data were expressed as frequency $(\%)$ or mean \pm standard deviation as appropriate. Comparisons between independent groups were performed using the independent samples $t$ test or the Mann-Whitney test as appropriate. Comparisons between paired groups were performed using the paired $t$ test. Dichotomous variables were analyzed using the $\chi^{2}$ test or the Fisher exact test as appropriate. Time-to-event analyses were performed using the Kaplan-Meier actuarial method. Comparison of the stratified Kaplan-Meier curves was performed using the log-rank test.

To overcome baseline differences, patients from each group were matched for comparison using propensity scores. The propensity score is a subject's probability of receiving a specific treatment (limited or conventional RV-tomy) conditional on the observed covariates. ${ }^{18}$ The propensity score was estimated using binary logistic regression with covariates of sex, age at TOF repair, and history of previous shunt. A matched sample was created by matching patients from each group on the logit of the propensity score using calipers of width equal to 0.2 of the standard deviation of the logit of the propensity score. ${ }^{18}$ Greedy nearest-neighbor matching without replacement was used to form pairs of matched patients. After matching, the balance in the baseline covariates between the groups was assessed using standardized difference and the groups were considered balanced if the standardized difference was less than $0.1{ }^{19}$ Paired $t$ tests were used to estimate the effect of treatment on the outcomes.

\section{RESULTS}

\section{Data at MRI Examination}

New York Heart Association functional class was I in 63 patients, II in 46, III in 1, and not available for 3 patients. Grade of tricuspid regurgitation assessed by echocardiography was none in 13 patients, trivial in 42 , mild in 57 , and not 
available in 1 . Only 1 patient in the conventional RV-tomy group showed a peak pressure gradient across the RV outflow tract greater than $40 \mathrm{~mm} \mathrm{Hg}$. Electrocardiographic data were available for 76 patients $(67.3 \%)$, and the mean QRS duration was $141 \pm 29$ milliseconds. Cardiopulmonary exercise test data were available for 47 patients $(41.6 \%)$, and the mean peak oxygen consumption was 30 $\pm 6 \mathrm{~mL} / \mathrm{kg} / \mathrm{min}(73 \% \pm 17 \%$ of the predicted value $)$.

\section{Analyses of MRI Parameters}

Table 1 shows MRI data for the study population and an overall comparison between patients with limited versus conventional RV-tomy. The mean age at the time of TOF repair was younger in the limited RV-tomy group. The mean interval between TOF repair and MRI examination was shorter in the limited RV-tomy group. PR fraction and indexed RV volumes were not statistically different between the groups. There was no statistically significant difference in the RV ejection fraction (EF) between the groups.

Thirty-nine patients from each group could be matched for comparison using the propensity score and the groups were well balanced for covariates of sex, age at the time of TOF repair, and history of previous shunt (Table 2). The propensity score matched comparison also revealed no significant differences in PR fraction, indexed RV volumes, and RV EF despite the shorter interval between TOF repair and MRI examination in the limited RV-tomy group.

\section{Clinical Outcomes}

Follow-up completeness measured by calculating the Clark index ${ }^{20}$ was $92.8 \%$. The mean follow-up duration was shorter in the limited RV-tomy group $(14.5 \pm 3.5$ years vs $21.1 \pm 4.2$ years; $P<.001)$. Fifteen patients in the limited
$\mathrm{RV}$-tomy group and 54 patients in the conventional RV-tomy group underwent PVR because of PR. Freedom from PVR at 20 years was $29.5 \% \pm 14.5 \%$ for the limited RV-tomy group and $38.1 \% \pm 6.2 \%$ for the conventional RV-tomy group $(P=.213$; Figure 2$)$. Two patients in the conventional RVtomy group underwent reoperation for RV outflow tract obstruction during follow-up (no difference in freedom from reoperation for $\mathrm{RV}$ outflow tract obstruction between the 2 groups; $P=.468$ ). One patient in the limited RVtomy group died of ischemic brain injury after PVR (no difference in survival between the 2 groups; $P=.163$ ). Two patients in the conventional RV-tomy group developed atrial flutter/fibrillation during follow-up (no difference in freedom from arrhythmia between the 2 groups; $P=.371$ ). There was no difference in QRS duration between the limited and the conventional RV-tomy groups $(143 \pm 25$ milliseconds vs $141 \pm 32$ milliseconds; $P=.781$ ). No significant ventricular arrhythmias were detected during follow-up. There was no difference in the peak oxygen consumption between the limited and conventional RV-tomy groups $(29 \pm 6 \mathrm{~mL} / \mathrm{kg} /$ $\min$ vs $30 \pm 6 \mathrm{~mL} / \mathrm{kg} / \mathrm{min} ; P=.412$ ).

\section{DISCUSSION}

Although repair of TOF is being performed with excellent operative survival, well-documented long-term sequelae associated with chronic PR have emerged as great challenges for clinicians. ${ }^{5-13}$ However, despite this awareness of the late consequences of chronic PR, ventriculotomy with transannular patch remains the most prevalent technique currently used for TOF repair. ${ }^{3,4}$ The conventional transventricular approach with a large RV-tomy for TOF repair provides excellent exposure for closure of the VSD and relief of the RV outflow tract obstruction at the expense

TABLE 1. Magnetic resonance imaging data for the study population and overall comparison of patients with limited versus conventional right ventriculotomy

\begin{tabular}{|c|c|c|c|c|}
\hline Variable & All patients $(n=113)$ & Limited RV-tomy $(n=39)$ & Conventional RV-tomy $(n=74)$ & $P$ value \\
\hline Sex (male:female) & $64: 49$ & $21: 18$ & $43: 31$ & .664 \\
\hline Age at repair (y) & $2.8 \pm 3.4$ & $1.8 \pm 2.0$ & $3.3 \pm 3.9$ & .007 \\
\hline Shunt before repair & $8 / 113(7.1 \%)$ & $3 / 39(7.7 \%)$ & $5 / 74(6.8 \%)$ & 1.000 \\
\hline Age at MRI (y) & $18.5 \pm 6.6$ & $14.5 \pm 4.8$ & $20.6 \pm 6.5$ & $<.001$ \\
\hline BSA at MRI $\left(\mathrm{m}^{2}\right)$ & $1.53 \pm 0.28$ & $1.38 \pm 0.32$ & $1.61 \pm 0.22$ & $<.001$ \\
\hline Interval between repair and MRI (y) & $15.7 \pm 4.9$ & $12.7 \pm 3.8$ & $17.2 \pm 4.7$ & $<.001$ \\
\hline $\mathrm{PR}$ fraction $(\%)$ & $45 \pm 9^{*}$ & $43 \pm 10$ & $45 \pm 9^{*}$ & .270 \\
\hline $\mathrm{RV} \operatorname{EDVI}\left(\mathrm{mL} / \mathrm{m}^{2}\right)$ & $151 \pm 38$ & $149 \pm 31$ & $152 \pm 42$ & .704 \\
\hline $\operatorname{RV} \operatorname{ESVI}\left(\mathrm{mL} / \mathrm{m}^{2}\right)$ & $75 \pm 34$ & $70 \pm 24$ & $77 \pm 38$ & .313 \\
\hline $\mathrm{RV} \operatorname{EF}(\%)$ & $52 \pm 9$ & $54 \pm 9$ & $51 \pm 9$ & .160 \\
\hline LV EDVI $\left(\mathrm{mL} / \mathrm{m}^{2}\right)$ & $74 \pm 12$ & $72 \pm 11$ & $75 \pm 13$ & .212 \\
\hline $\operatorname{LV} \operatorname{ESVI}\left(\mathrm{mL} / \mathrm{m}^{2}\right)$ & $29 \pm 9$ & $26 \pm 7$ & $31 \pm 10$ & .009 \\
\hline $\operatorname{LV} \mathrm{EF}(\%)$ & $61 \pm 7$ & $64 \pm 6$ & $60 \pm 7$ & .002 \\
\hline RPA dimension $\left(\mathrm{mm} / \mathrm{m}^{2}\right)$ & $9.0 \pm 2.6 \dagger$ & $9.7 \pm 2.7$ & $8.6 \pm 2.5 \dagger$ & .027 \\
\hline LPA dimension $\left(\mathrm{mm} / \mathrm{m}^{2}\right)$ & $7.3 \pm 2.5 \dagger$ & $7.5 \pm 2.3$ & $7.2 \pm 2.6^{\dagger}$ & .569 \\
\hline
\end{tabular}

$R V$-tomy, Right ventriculotomy; $M R I$, magnetic resonance imaging; $B S A$, body surface area; $P R$, pulmonary regurgitation; $R V$, right ventricular; $E D V I$, end-diastolic volume index; $E S V I$, end-systolic volume index; $E F$, ejection fraction; $L V$, left ventricular; $R P A$, right pulmonary artery; $L P A$, left pulmonary artery. $*$ Data not available for 1 patient. $\dagger$ Data not available for 2 patients. 
TABLE 2. Propensity score matched comparison between patients with limited versus conventional right ventriculotomy

\begin{tabular}{|c|c|c|c|}
\hline & Limited RV-tomy $(\mathbf{n}=39)$ & Conventional RV-tomy $(n=39)$ & \\
\hline Covariates used for matching & & & SD \\
\hline Sex (male:female) & $21: 18$ & $21: 18$ & .000 \\
\hline Age at repair $(y)$ & $1.8 \pm 2.0$ & $1.9 \pm 2.3$ & .030 \\
\hline Shunt before repair, $\mathrm{n}(\%)$ & $3(7.7)$ & $3(7.7)$ & .000 \\
\hline MRI data & & & $P$ value \\
\hline Age at MRI (y) & $14.5 \pm 4.8$ & $18.3 \pm 4.6$ & $<.001$ \\
\hline BSA at MRI $\left(\mathrm{m}^{2}\right)$ & $1.38 \pm 0.32$ & $1.57 \pm 0.24$ & .002 \\
\hline Interval between repair and MRI $(y)$ & $12.7 \pm 3.8$ & $16.4 \pm 3.8$ & $<.001$ \\
\hline PR fraction $(\%)^{*}$ & $42 \pm 10$ & $46 \pm 9$ & .205 \\
\hline $\mathrm{RV} \operatorname{EDVI}\left(\mathrm{mL} / \mathrm{m}^{2}\right)$ & $149 \pm 31$ & $152 \pm 48$ & .757 \\
\hline $\operatorname{RV} \operatorname{ESVI}\left(\mathrm{mL} / \mathrm{m}^{2}\right)$ & $70 \pm 24$ & $77 \pm 46$ & .430 \\
\hline RV EF (\%) & $54 \pm 9$ & $52 \pm 10$ & .372 \\
\hline LV EDVI $\left(\mathrm{mL} / \mathrm{m}^{2}\right)$ & $72 \pm 11$ & $75 \pm 15$ & .365 \\
\hline $\operatorname{LV} \operatorname{ESVI}\left(\mathrm{mL} / \mathrm{m}^{2}\right)$ & $26 \pm 7$ & $30 \pm 12$ & .076 \\
\hline $\operatorname{LV} \mathrm{EF}(\%)$ & $64 \pm 6$ & $61 \pm 8$ & .037 \\
\hline RPA dimension $\left(\mathrm{mm} / \mathrm{m}^{2}\right) \dagger$ & $9.7 \pm 2.8$ & $8.3 \pm 2.2$ & .010 \\
\hline LPA dimension $\left(\mathrm{mm} / \mathrm{m}^{2}\right) \dagger$ & $7.3 \pm 2.2$ & $6.6 \pm 2.1$ & .189 \\
\hline
\end{tabular}

$S D$, Standardized difference; $R V$-tomy, right ventriculotomy; $M R I$, magnetic resonance imaging; $B S A$, body surface area; $P R$, pulmonary regurgitation; $R V$, right ventricular; $E D V I$, end-diastolic volume index; $E S V I$, end-systolic volume index; $E F$, ejection fraction; $L V$, left ventricular; RPA, right pulmonary artery; $L P A$, left pulmonary artery. *Data not available for 1 pair. $\dagger$ Data not available for 2 pairs.

of increased risk of RV dysfunction and ventricular arrhythmias in the long term. The transatrial transpulmonary approach has thus been popularized to avoid or minimize such problems by avoiding or limiting RV-tomy. Some studies have suggested short-term benefits of limited RVtomy compared with conventional RV-tomy in terms of RV volume and function. ${ }^{15,21}$ In this context, it is possible to hypothesize that limited RV-tomy in the setting of transannular TOF repair might also result in less RV dilatation and

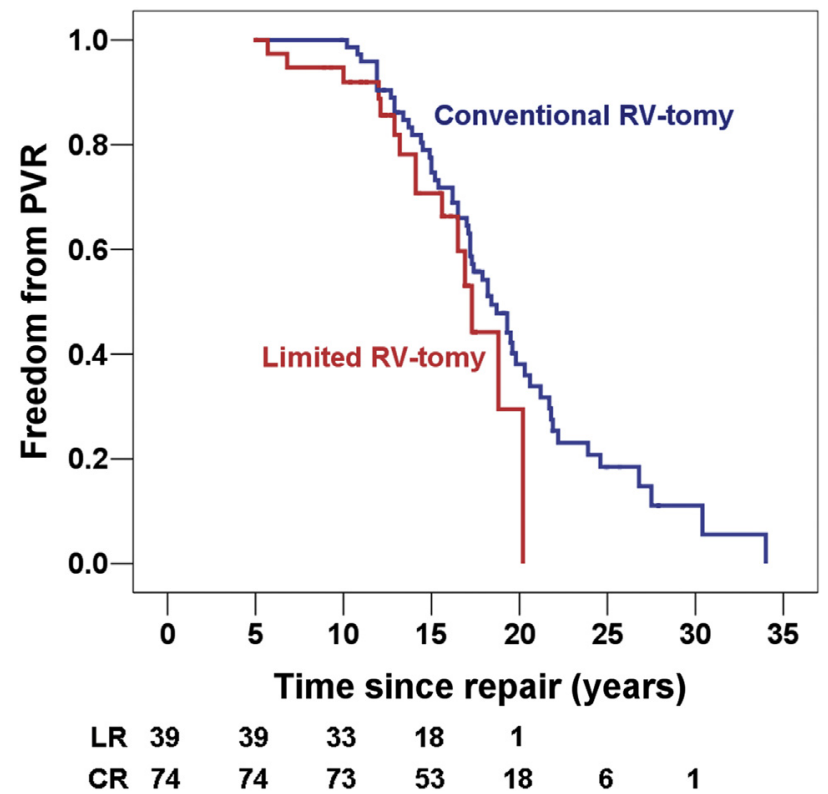

FIGURE 2. Freedom from pulmonary valve replacement $(P V R)$ according to the type of right ventriculostomy ( $R V$-tomy). Numbers below the graph represent patients remaining at risk. $L R$, Limited $\mathrm{RV}$-tomy; $C R$, conventional RV-tomy. dysfunction compared with conventional RV-tomy in the long term. However, such a hypothesis has not been clearly demonstrated to date and the present study was conducted to test this hypothesis.

To our knowledge, there have been no studies comparing RV volume and function measured by MRI, which is the gold standard for evaluating these parameters, between patients with limited and conventional RV-tomy in the long term after transannular repair of TOF. Contrary to our initial expectation, we found that limited RV-tomy in the setting of transannular TOF repair did not show long-term benefits compared with conventional RV-tomy in terms of RV volume and function. In addition, there were no differences in clinical outcomes such as late survival, rate of PVR, arrhythmia, and exercise capacity between the 2 groups. These results were unexpected, because numerous studies have already shown the detrimental role of RV outflow tract patch or dysfunction in patients with repaired TOF. ${ }^{22-28}$

\section{Detrimental Role of RV Outflow Tract Patch or Dysfunction}

In a long-term follow-up study of 191 patients who had undergone transventricular repair of TOF, d'Udekem and colleagues ${ }^{23}$ found that direct closure of the RV-tomy achieved better freedom from adverse events (cardiac death, PVR, and impaired functional status) than transannular or RV patching. They found that there was no difference between RV and transannular patching with regard to late clinical outcome, RV size, or incidence of severe PR. Similarity in the outcomes of patients with an RV patch and those with a transannular patch has also been described by others. ${ }^{22,24}$ From this study, they raised the hypothesis that RV infundibular contractility might play a key role in protection of the RV against 
deleterious consequences of the chronic volume overload related to PR. This hypothesis was further supported by their another study comparing patients who had undergone pulmonary commissurotomy for isolated pulmonary stenosis or transventricular repair of TOF. ${ }^{25}$ In that study, it was found that freedom from adverse events (cardiac death, PVR, and impaired functional status) was better in patients with isolated commissurotomy despite similar degrees of PR. Recently, Puranik and colleagues ${ }^{28}$ reported an MRI study comparing patients who underwent transannular repair of TOF with patients who underwent surgical or percutaneous valvotomy for valvular pulmonary stenosis. They found that, although PR fractions and indexed RV end-diastolic volumes were similar between the groups, indexed RV end-systolic volume was higher and RV EF was lower in patients with TOF compared with pulmonary stenosis. These findings also suggest the detrimental effect of RV outflow tract contractile dysfunction on global RV function, although completely different disease entities were compared.

\section{Explanations for the Findings of This Study}

Based on the studies mentioned earlier, it is reasonable to hypothesize that limited RV-tomy in the setting of transannular TOF repair, compared with conventional RV-tomy, might protect patients from progressive RV dilatation and dysfunction in the long term. However, our study failed to prove this hypothesis. There are a few explanations for this. First, preservation of pulmonary valve function might be more important than a 1- to 2-cm difference in the length of transannular RV-tomy. A transannular patch inevitably causes PR. Although PR will be less initially if a transannular patch is small, it may get worse as the patient grows. In a mid-tolate follow-up study of 59 patients who had undergone transatrial transpulmonary repair of TOF (transannular patch in $71 \%$ ), van den Berg and colleagues ${ }^{29}$ found that these patients showed RV dilatation and dysfunction assessed by MRI and that larger RV dilatation and poorer RV EF were associated with a longer interval since repair. They speculated that, even in patients with TOF corrected according to current surgical strategies, gradual deterioration of RV function with volume overload seemed inevitable. RV volume and function in patients with a limited transannular patch in their study were similar to those in patients with a conventional transannular patch in our study, although such a comparison can be problematic. Second, aggressive resection of RV outflow tract muscle bundles might contribute more to late RV dilatation and dysfunction than the extent of RVtomy. In a study assessing RV volume and function with MRI in 85 patients with repaired TOF, Davlouros and colleagues $^{24}$ found that RV outflow tract aneurysm or akinesia was related in part to RV outflow tract or transannular patching and that RV outflow tract aneurysm or akinesia was associated with RV dilatation and dysfunction. They have shown that RV outflow tract aneurysm or akinesia was also present in a significant number of patients who did not undergo a patch type of repair and speculated that other factors, such as extreme infundibular resection with or without ischemic insult (perhaps caused by conal branch interruption), were also responsible for the genesis of RV outflow tract aneurysm or akinesia. In an MRI study evaluating different adaptations of the 3 components of the RV to chronic volume overload after TOF repair, Bodhey and colleagues ${ }^{26}$ found that there was significant increase in end-systolic volume and decrease in the EF of the RV outlet component compared with healthy controls. They also found that these changes were not affected by the surgical technique (infundibulectomy only vs infundibulectomy with transannular patch). Third, although preserving RV infundibular function in TOF repair has been emphasized, ${ }^{17,30}$ the exact contribution of the infundibulum, in which a transannular incision is made, to global RV function is controversial. In an MRI study of systolic RV function in young individuals without heart disease, Geva and colleagues ${ }^{31}$ demonstrated that the infundibulum contributed to only $13 \%$ of the total RV stroke volume. Bodhey and colleagues ${ }^{26}$ found that stroke volume of the infundibulum was $25 \%$ of the total RV stroke volume in healthy individuals.

\section{Outcomes of the Transatrial Versus Transventricular Approach for TOF Repair}

There are few studies comparing the outcomes of the transatrial approach versus the transventricular approach (ie, limited RV-tomy vs conventional transannular RVtomy) for TOF repair. ${ }^{32-34}$ In a midterm follow-up study using angiography, Miura and colleagues ${ }^{32}$ found that the transatrial approach provided better postoperative global $\mathrm{RV}$ function and its reserve, with less impaired regional wall motion, than the transventricular approach. In a longterm follow-up study, Atallah-Yunes and colleagues ${ }^{33}$ found that the transatrial approach with a small RV incision $(<2 \mathrm{~cm})$ resulted in significantly less $\mathrm{RV}$ dilatation and better preservation of RV function, as assessed by echocardiography, compared with the transventricular approach with a large RV incision (half the length of the RV). In a midterm follow-up study, Alexiou and colleagues ${ }^{34}$ reported that transventricular and transatrial repair were both associated with a low incidence of late arrhythmias, good biventricular function, and excellent survival. However, they found that the transatrial approach had a disturbing incidence of early and midterm RV outflow tract obstruction, probably caused by inadequate RV outflow tract muscle resection, even when a transannular patch was used.

There is no long-term follow-up study evaluating the outcomes of transatrial transpulmonary TOF repair and only a few midterm follow-up studies have been reported recently. ${ }^{30,35}$ In a study of 140 patients who had undergone transatrial transpulmonary repair of TOF, Bové and colleagues $^{30}$ reported that increased length of the 
transannular incision was an independent risk factor for late RV dilatation assessed by echocardiography and that a side effect of the adoption of an RV outflow tract-sparing policy in their series was a higher reoperation rate for residual or recurrent RV outflow tract obstruction. In a study of 245 patients who had undergone transatrial transpulmonary repair of TOF (transannular patch in 74\%), Sfyridis and colleagues ${ }^{35}$ reported that the rate of PVR was relatively low, RV function remained well preserved, and significant arrhythmias were not encountered. In contrast to previous studies, ${ }^{30,34}$ they did not find the problem of residual or recurrent RV outflow tract obstruction. They have also reported that, in patients who had a transannular patch, there was no influence of the degree of transannular extension $(<10 \mathrm{~mm}$ or $10-15 \mathrm{~mm})$ on the rate of late PVR. They speculated that even a minimal incision through the pulmonary valve annulus onto the RV infundibulum might lead to progressive PR and more PVR might become necessary in the future. Because randomized trials comparing different surgical approaches for TOF repair are not likely to be conducted in the future, long-term followup studies clearly elucidating the outcomes of the transatrial transpulmonary approach with limited transannular incision are worth waiting for. In addition, because the transannular patch remains the most prevalent technique currently used for TOF repair, ${ }^{3,4}$ more efforts should be made to preserve pulmonary valve function, just like the efforts currently being made to limit the extent of transannular RV-tomy.

\section{Limitations of the Study}

The study is limited by its retrospective nature. The present study population does not represent the entire spectrum of patients who underwent transannular TOF repair, because only the patients who had undergone MRI examination were included. Because of the relatively small number of patients in the limited RV-tomy group, the study might have been underpowered to detect differences in MRI parameters between the 2 groups. Similarly, because electrocardiographic data were available in only $67 \%$ of the study population and cardiopulmonary exercise test data in only $42 \%$, there may not have been adequate power to detect differences between the 2 groups. Many surgeons were involved in the repair of our study patients. Therefore, repair techniques, such as width of the transannular patch and removal of the pulmonary valve leaflets, were not constant. Such technical details other than the length of RV incision might also have influenced the long-term outcomes of our patients. Much longer follow-up is mandatory to draw definitive conclusions about the effect of the extent of RV-tomy on clinical outcomes such as arrhythmias and late survival.

\section{CONCLUSIONS}

No long-term benefits of limited RV-tomy were demonstrated compared with conventional RV-tomy in patients who underwent transannular TOF repair, at least in terms of RV volume and function. However, the findings of our study should not be interpreted as discouraging the use of the transatrial transpulmonary approach for TOF repair. Further studies are necessary to define the role of limited RV-tomy in patients who undergo transannular TOF repair.

\section{References}

1. Murphy JG, Gersh BJ, Mair DD, Fuster V, McGoon MD, Ilstrup DM, et al. Longterm outcome in patients undergoing surgical repair of tetralogy of Fallot. $N$ Engl J Med. 1993;329:593-9.

2. Park CS, Lee JR, Lim HG, Kim WH, Kim YJ. The long-term results of total repair for tetralogy of Fallot. Eur J Cardiothorac Surg. 2010;38:311-7.

3. Al Habib HF, Jacobs JP, Mavroudis C, Tchervenkov CI, O'Brien SM, Mohammadi S, et al. Contemporary patterns of management of tetralogy of Fallot: data from the Society of Thoracic Surgeons Database. Ann Thorac Surg. 2010;90:813-20.

4. Sarris GE, Comas JV, Tobota Z, Maruszewski B. Results of reparative surgery for tetralogy of Fallot: data from the European Association for Cardio-Thoracic Surgery Congenital Database. Eur J Cardiothorac Surg. 2012;42:766-74.

5. Gatzoulis MA, Balaji S, Webber SA, Siu SC, Hokanson JS, Poile C, et al. Risk factors for arrhythmia and sudden cardiac death late after repair of tetralogy of Fallot: a multicentre study. Lancet. 2000;356:975-81.

6. Geva T, Sandweiss BM, Gauvreau K, Lock JE, Powell AJ. Factors associated with impaired clinical status in long-term survivors of tetralogy of Fallot repair evaluated by magnetic resonance imaging. J Am Coll Cardiol. 2004;43:1068-74.

7. Bouzas B, Kilner PJ, Gatzoulis MA. Pulmonary regurgitation: not a benign lesion. Eur Heart J. 2005;26:433-9.

8. Lee C, Jacobs JP, Lee CH, Kwak JG, Chai PJ, Quintessenza JA. Surgical pulmonary valve insertion-when, how, and why. Cardiol Young. 2012;22:702-7.

9. Oosterhof T, van Straten A, Vliegen HW, Meijboom FJ, van Dijk AP, Spijkerboer AM, et al. Preoperative thresholds for pulmonary valve replacement in patients with corrected tetralogy of Fallot using cardiovascular magnetic resonance. Circulation. 2007; 116:545-51.

10. Frigiola A, Tsang V, Bull C, Coats L, Khambadkone S, Derrick G, et al. Biventricular response after pulmonary valve replacement for right ventricular outflow tract dysfunction: is age a predictor of outcome? Circulation. 2008;118(14 Suppl):S182-90.

11. Lee C, Kim YM, Lee CH, Kwak JG, Park CS, Song JY, et al. Outcomes of pulmonary valve replacement in 170 patients with chronic pulmonary regurgitation after relief of right ventricular outflow tract obstruction: implications for optimal timing of pulmonary valve replacement. J Am Coll Cardiol. 2012;60:1005-14.

12. Dos L, Dadashev A, Tanous D, Ferreira-González IJ, Haberer K, Siu SC, et al. Pulmonary valve replacement in repaired tetralogy of Fallot: determinants of early postoperative adverse outcomes. J Thorac Cardiovasc Surg. 2009;138: 553-9.

13. Lee C, Park CS, Lee CH, Kwak JG, Kim SJ, Shim WS, et al. Durability of bioprosthetic valves in the pulmonary position: long-term follow-up of 181 implants in patients with congenital heart disease. J Thorac Cardiovasc Surg. 2011;142: 351-8.

14. Karl TR, Sano S, Pornviliwan S, Mee RB. Tetralogy of Fallot: favorable outcome of nonneonatal transatrial, transpulmonary repair. Ann Thorac Surg. 1992;54: 903-7.

15. Stellin G, Milanesi O, Rubino M, Michielon G, Bianco R, Moreolo GS, et al. Repair of tetralogy of Fallot in the first six months of life: transatrial versus transventricular approach. Ann Thorac Surg. 1995;60(6 Suppl):S588-91.

16. Hirsch JC, Mosca RS, Bove EL. Complete repair of tetralogy of Fallot in the neonate: results in the modern era. Ann Surg. 2000;232:508-14.

17. Morales DL, Zafar F, Fraser CD Jr. Tetralogy of Fallot repair: the Right Ventricle Infundibulum Sparing (RVIS) strategy. Semin Thorac Cardiovasc Surg Pediatr Card Surg Annu. 2009;54-8.

18. Austin PC. Propensity-score matching in the cardiovascular surgery literature from 2004 to 2006: a systematic review and suggestions for improvement. $J$ Thorac Cardiovasc Surg. 2007; 134:1128-35.

19. Austin PC. Balance diagnostics for comparing the distribution of baseline covariates between treatment groups in propensity-score matched samples. Stat Med. 2009;28:3083-107.

20. Clark TG, Altman DG, De Stavola BL. Quantification of the completeness of follow-up. Lancet. 2002;359:1309-10. 
21. Kawashima Y, Kitamura S, Nakano S, Yagihara T. Corrective surgery for tetralogy of Fallot without or with minimal right ventriculotomy and with repair of the pulmonary valve. Circulation. 1981;64(2 Pt 2):II147-53.

22. Nollert G, Fischlein T, Bouterwek S, Böhmer C, Klinner W, Reichart B. Longterm survival in patients with repair of tetralogy of Fallot: 36-year follow-up of 490 survivors of the first year after surgical repair. J Am Coll Cardiol. 1997; 30:1374-83.

23. d'Udekem Y, Ovaert C, Grandjean F, Gerin V, Cailteux M, Shango-Lody P, et al. Tetralogy of Fallot: transannular and right ventricular patching equally affect late functional status. Circulation. 2000;102(Suppl 3):III116-22.

24. Davlouros PA, Kilner PJ, Hornung TS, Li W, Francis JM, Moon JC, et al. Right ventricular function in adults with repaired tetralogy of Fallot assessed with cardiovascular magnetic resonance imaging: detrimental role of right ventricular outflow aneurysms or akinesia and adverse right-to-left ventricular interaction. J Am Coll Cardiol. 2002;40:2044-52.

25. d'Udekem d'Acoz Y, Pasquet A, Lebreux L, Ovaert C, Mascart F, Robert A, et al. Does right ventricular outflow tract damage play a role in the genesis of late right ventricular dilatation after tetralogy of Fallot repair? Ann Thorac Surg. 2003;76: 555-61.

26. Bodhey NK, Beerbaum P, Sarikouch S, Kropf S, Lange P, Berger F, et al. Functional analysis of the components of the right ventricle in the setting of tetralogy of Fallot. Circ Cardiovasc Imaging. 2008;1:141-7.

27. Wald RM, Haber I, Wald R, Valente AM, Powell AJ, Geva T. Effects of regional dysfunction and late gadolinium enhancement on global right ventricular function and exercise capacity in patients with repaired tetralogy of Fallot. Circulation. 2009;119:1370-7.

28. Puranik R, Tsang V, Lurz P, Muthurangu V, Offen S, Frigiola A, et al. Long-term importance of right ventricular outflow tract patch function in patients with pulmonary regurgitation. J Thorac Cardiovasc Surg. 2012;143:1103-7.

29. van den Berg J, Hop WC, Strengers JL, de Jongste JC, van Osch-Gevers L, Meijboom FJ, et al. Clinical condition at mid-to-late follow-up after transatrial-transpulmonary repair of tetralogy of Fallot. J Thorac Cardiovasc Surg. 2007; 133:470-7.

30. Bové T, François K, Van De Kerckhove K, Panzer J, De Groote K, De Wolf D, et al. Assessment of a right-ventricular infundibulum-sparing approach in transatrial-transpulmonary repair of tetralogy of Fallot. Eur $J$ Cardiothorac Surg. 2012;41:126-33.

31. Geva T, Powell AJ, Crawford EC, Chung T, Colan SD. Evaluation of regional differences in right ventricular systolic function by acoustic quantification echocardiography and cine magnetic resonance imaging. Circulation. 1998;98:339-45.

32. Miura T, Nakano S, Shimazaki Y, Kobayashi J, Hirose H, Sano T, et al. Evaluation of right ventricular function by regional wall motion analysis in patients after correction of tetralogy of Fallot. Comparison of transventricular and nontransventricular repairs. J Thorac Cardiovasc Surg. 1992;104:917-23.

33. Atallah-Yunes NH, Kavey RE, Bove EL, Smith FC, Kveselis DA, Byrum CJ, et al. Postoperative assessment of a modified surgical approach to repair of tetralogy of Fallot. Long-term follow-up. Circulation. 1996;94(9 Suppl):II22-6.

34. Alexiou C, Chen Q, Galogavrou M, Gnanapragasam J, Salmon AP, Keeton BR, et al. Repair of tetralogy of Fallot in infancy with a transventricular or a transatrial approach. Eur J Cardiothorac Surg. 2002;22:174-83.

35. Sfyridis PG, Kirvassilis GV, Papagiannis JK, Avramidis DP, Ieromonachos CG, Zavaropoulos PN, et al. Preservation of right ventricular structure and function following transatrial-transpulmonary repair of tetralogy of Fallot. Eur J Cardiothorac Surg. 2013;43:336-42.

\section{Discussion}

Dr Tom R. Karl (Brisbane, Australia). Thank you for your elegant presentation. In your talk you contend that the nonindexed extent of the right ventricular incision and the approach to VSD closure in tetralogy of Fallot have no influence on late RV systolic and diastolic volumes. Many groups feel that the transventricular approach to VSD closure in tetralogy is primarily of historical interest; these results would certainly seem disappointing to advocates of transatrial transpulmonary repair. We may have some issues with the interpretation of the data or perhaps with the selection of patients. The Royal Children's Hospital ( $\mathrm{RCH})$ cohort originally described in the 1992 article cited in your presentation have been followed up to the current time and the 25-year actuarial freedom from reintervention for pulmonary valve implant is about $85 \%$ and from reoperation for right ventricular outflow tract obstruction about $89 \%$. So we stand by the statements that we made in the 1992 publication, and I thank the current RCH team for providing the data.

What was the indication for MRI in your patients and did the probability of undergoing MRI differ between the two cohorts? With propensity score matching you can get a lot of useful information, but in this case you have not accounted for the year of operation, which you have stated might be important, because there was a trend for use of the transatrial transpulmonary repair in the later part of the series.

Likewise, to isolate the effect of the ventriculotomy itself, one would have to account for the degree of pulmonary insufficiency immediately after repair to establish a baseline. I wonder if this factor was taken into account?

And lastly, the Sung repair, an excellent Korean contribution, has become the standard of care for tetralogy patients in my own unit. I wonder if limitation of pulmonary insufficiency was attempted by way of valve reconstruction in any patients in your study as part of the right ventricular outflow tract repair?

Dr Lee. Thank you very much for your excellent comments, Tom.

For the first question, I think that's a very good point to start. The present study population does not represent the entire spectrum of patients who underwent tetralogy repair during the same period because only patients with MRI were included in the study. I know that this is one of the limitations of our study.

Usually our cardiologists prescribed MRI to accurately assess $\mathrm{RV}$ volume and function and to determine the timing of pulmonary valve replacement when they found a significantly dilated right ventricle on follow-up echocardiography. Therefore, if there is a significant difference in the proportion of patients who underwent MRI between the two groups, for example, $30 \%$ for the conventional RV-tomy group and $10 \%$ for the limited RV-tomy group, one can argue that comparison between such groups with MRI examination can be misleading. So I looked back to our original cohort of patients and found that about $9 \%$ of the patients with transatrial repair and about $11 \%$ of the patients with transventricular repair underwent MRI examination. I think that this is not a big difference and comparing the two groups who had undergone MRI examination might not have distorted the entire picture of the patient population.

For the second question about the year of operation, I agree that the year of operation should be considered in the analysis. Over the 20 years in which repair was performed on these patients, many things have changed, such as techniques of repair, methods of myocardial protection, surgeons doing the repair, and details of postoperative management. I think that all these changes might have influenced the long-term outcomes of the patients included in the study. However, including the year of operation in the propensity score model might have produced a very small number of matched pairs for comparison. So we did not include the year of operation to obtain adequate statistical power of the analysis.

For the third question: what was the third question?

Dr Karl. The third question was about trying to separate the effect of the ventriculotomy from the effect of pulmonary insufficiency immediately after the operation and whether it would be possible or advisable to do that in such a study. 
Dr Lee. I don't have detailed data to answer that question, sorry.

Dr Karl. And the last question was whether you had attempted any type of valve reconstruction?

Dr Lee. I know that technique, Sung's technique for valve repair at the time of transannular RV outflow tract reconstruction. In our patient cohort, no patients underwent valve repair at the time of transannular reconstruction; however, one of my colleagues in our center is doing that kind of repair using GoreTex membrane. I think that's a very good option at the time of transannular repair.

Dr Karl. Thank you. You've answered the questions very well.

Dr Christian Brizard (Melbourne, Australia). Tom, it is my duty to advocate for transatrial transpulmonary repair. The essence of the transatrial repair is to preserve the right ventricle by two means: a limited ventriculotomy allows a relatively small pulmonary orifice, it preserves the epicardium and therefore the coronary supply to the infundibulum, but it is also a way to preserve some degree of stenosis in the infundibulum. We believe that the essence of the transatrial repair is to preserve some degree of stenosis that will allow for preservation of the ventricular mass and a mildly reduced RV compliance, which in turn, will contain the pulmonary regurgitation.

You have provided a very extensive set of data, but there is no mention of a gradient in the right ventricular outflow tract. And you will hear tomorrow that there are many ways to skin a cat. A transatrial repair can be done leaving significant residual stenosis, or it can be done with very extensive resection without a residual gradient; in that case, the transatrial repair is really not different from a transventricular repair. So I think in your data it is very important for the comprehension of your results whether there is a residual gradient or not.

Dr Lee. Thank you. For our study patients, there was no significant RV outflow tract obstruction in patients who underwent transatrial repair of tetralogy. I agree with your opinion that leaving some degree of RV outflow tract stenosis might be important for the future prevention of severe pulmonary regurgitation and RV dysfunction.
Dr Brizard. Thank you.

Dr Pedro J. del Nido (Boston, Mass). If I could follow up on that question, because the concept of leaving some degree of stenosis at the time of original repair has been brought up before, but it's curious to see that the problem occurs 10 to 12 years later when that stenosis is no longer relevant.

Looking specifically at the degree of pulmonary regurgitation, were there differences in the volume of regurgitation when you did the MRI in the transannular versus the minimal incision versus the conventional repair?

Dr Lee. There was no significant difference in the pulmonary regurgitation fraction between the two groups.

Dr del Nido. Well, I'm thinking more of the volume, the actual volume, rather than the fraction.

Dr Lee. Sorry, I don't have data to answer that.

Dr del Nido. Because that would argue strongly that it's about lack of a valve rather than the extent of the incision.

Dr Christopher A. Caldarone (Toronto, Ontario, Canada). Reading this abstract, one would have anticipated that the regurgitant fraction would have been larger in the patients with conventional ventriculotomy but that wasn't the case. So an alternative way to interpret all the data would be that there really wasn't much difference between the groups, and the right ventriculotomy is similar in both groups. Do you have more information about how big the ventriculotomies were in the patients in the conventional group?

Dr Lee. Unfortunately, I don't have accurate information about the actual length of the RV incisions, for example, $8 \mathrm{~mm}$ for patient A, $5 \mathrm{~mm}$ for patient B, so that we can get an indexed $\mathrm{RV}$ incision length. All we know is that for the patient with limited RV incision, the incision length was less than $1 \mathrm{~cm}$, because we closed the VSD through the right atrium. And for the conventional RV-tomy group, it was much bigger, probably 2 to $3 \mathrm{~cm}$, because the VSD was closed, should be closed, through the right ventricle. 